\title{
Conventional Approach Versus Lensectomy with Anterior Vitrectomy in Congenital Cataract - A Comparative Study from Meerut, India
}

\author{
Satendri Devi' ${ }^{1}$ Lokesh Kumar Singh ${ }^{2}$, Alka Gupta ${ }^{3}$ \\ 1,2,3 Department of Ophthalmology, LLRM Medical College, Meerut, Uttar Pradesh, India.
}

\section{ABSTRACT}

\section{BACKGROUND}

We wanted to compare lensectomy with anterior vitrectomy and conventional methods in the surgical management of congenital cataract.

\section{METHODS}

The present study is an interventional analytical study that entailed 30 patients $(33$ eyes) of bilateral or unilateral congenital cataract who attended the Ophthalmology outpatient department of LLRM Medical College, Meerut, during the period extending from March 2018 to March 2019. 19 of these patients (63.3 \%) were males while 11 $(36.7 \%)$ were females. Age of the patients varied from 2 years to 12 years, with a mean age of 5 years 7 months. The maximum number of patients was in the age group of 4 - 8 years in either sex.

\section{RESULTS}

Being a comparative analysis, this study had $39.3 \%$ cases treated by conventional methods and $60.7 \%$ cases managed by lensectomy and anterior vitrectomy. The visual acuity was compared in the conventionally treated patients and lensectomy and anterior vitrectomy treated patients. Amongst the patients managed by conventional methods, $37.5 \%$ had good vision, $12.5 \%$ had fair vision and $50.0 \%$ poor vision. In the lensectomy and anterior vitrectomy treated group, $61.1 \%$ cases had good vision, $22.2 \%$ had fair vision and only $16.7 \%$ had poor vision. Comparing the occurrence of complications in both groups, the conventionally treated group showed an incidence of $32.4 \%$ as compared to $4.4 \%$ in lensectomy and anterior vitrectomy treated group.

\section{CONCLUSIONS}

The lensectomy and anterior vitrectomy treated groups had good vision and fewer complications as compared to the conventional methods.

\section{KEY WORDS}

Cataract, Visual Acuity, Lensectomy, Vitrectomy
Corresponding Author:

Dr. Satendri Devi,

Department of Ophthalmology,

LLRM, Medical College,

Meerut - 250004

Uttar Pradesh, India

E-mail: shikhalok.devi@gmail.com

DOI: $10.14260 / j e m d s / 2021 / 466$

How to Cite This Article:

Devi S, Singh LK, Gupta A. Conventional approach versus lensectomy with anterior vitrectomy in congenital cataract - a comparative study from Meerut, India. J Evolution Med Dent Sci 2021;10(30):22812285, DOI: 10.14260/jemds/2021/466

Submission 06-07-2020,

Peer Review 24-05-2021,

Acceptance 31-05-2021,

Published 26-07-2021.

Copyright (c) 2021 Satendri Devi et al. This is an open access article distributed under Creative Commons Attribution License [Attribution 4.0 International (CC BY 4.0)] 


\section{BACKGROUND}

Fighting childhood blindness from congenital cataracts is a priority of Vision 2020: The Right to Sight, a global initiative aimed at reducing the world's burden of avoidable blindness. ${ }^{1}$ Congenital cataracts occur when visual development is in its sensitive and critical stages, ${ }^{2}$ therefore, applying inappropriate surgical interventions in children may not only fail to restore visual function but also cause irreversible effects on eyeball development. ${ }^{3}$ Cataracts that are present at birth or that develop within the first year of life are called congenital cataracts. Paediatric cataract is a treatable leading cause of childhood blindness. It accounts for $7.4 \%-15.3 \%$ of paediatric blindness and a significant avertable disability adjusted life year.4,5 The overall prevalence of congenital cataract ranges from 0.63 to $9.74 / 10000 .{ }^{6}$

While, the incidence ranges from 1.8 to 3.6 / 10000 per year. ${ }^{1}$ It has been found that during pregnancy, $67 \%$ of the mothers had a history of illness and $22 \%$ had taken medications during pregnancy.7,8 Congenital cataract is associated with ocular abnormalities in $27 \%$ of cases and with systemic abnormalities in $22 \%$ of cases. The diagnosis of cataract is incidentally made on routine screening in $41 \%$ of cases whereas leukocoria and strabismus led to the diagnosis in $24 \%$ and $19 \%$, respectively. ${ }^{9}$ A key period for visual development is the first 6 weeks of life, and extraction of cataract within the first $6-10$ weeks of life can prevent the risk of development of stimulus deprivation amblyopia, strabismus, and nystagmus. ${ }^{10}$ Congenital cataracts may be unilateral or bilateral. They can be classified by morphology, presumed, or defined genetic aetiology, presence of specific metabolic disorders, or associated ocular anomalies or systemic findings. Congenital cataracts occur in a variety of morphologic configurations, including lamellar, polar, sutural, coronary, cerulean, nuclear, capsular, complete, and membranous.

\begin{tabular}{|c|c|c|c|c|}
\hline Whole Lens & Central & Anterior & Posterior & Miscellaneous \\
\hline Total & Lamellar & Anterior polar & Mittendorf dots & $\begin{array}{c}\text { Punctate lens } \\
\text { Opacities }\end{array}$ \\
\hline $\begin{array}{c}\text { Congenital } \\
\text { Morgagnian }\end{array}$ & $\begin{array}{c}\text { Central } \\
\text { Pulverulent }\end{array}$ & Don't like & $\begin{array}{l}\text { Posterior } \\
\text { cortical }\end{array}$ & Sutural \\
\hline \multirow[t]{6}{*}{ Membranous } & Ant egg & Plaque like & $\begin{array}{c}\text { Posterior } \\
\text { Subcapsular }\end{array}$ & Coralliform \\
\hline & Nuclear & $\begin{array}{l}\text { Anterior } \\
\text { Pyramidal }\end{array}$ & $\begin{array}{l}\text { Posterior } \\
\text { Lenticonus }\end{array}$ & Wedge Shaped \\
\hline & Oil Droplet & $\begin{array}{l}\text { Anterior } \\
\text { subcapsular }\end{array}$ & & $\begin{array}{c}\text { Persistent } \\
\text { Hyperplastic } \\
\text { Primary Vitreous }\end{array}$ \\
\hline & Cortical & $\begin{array}{l}\text { Anterior } \\
\text { lenticonus }\end{array}$ & & \\
\hline & Coronary & & & \\
\hline & Table & orpholog & Cataract & \\
\hline
\end{tabular}

The paediatric cataract is soft and can be easily aspirated by phacoaspiration. ${ }^{11}$ Posterior capsule opacification is also more common after paediatric cataract surgery than after age - related cataract surgery. ${ }^{12}$ Hence additional procedures, such as polishing of the lens capsule, posterior laser capsulotomy, primary posterior capsulotomy, or anterior vitrectomy are widely practised to prevent posterior capsule opacification. ${ }^{4}$ Different conventional modalities of treating congenital cataracts have had their period of vogue and disrepute. These include optical iridectomy, discission ('needling'), Ziegler through and through discission, intracapsular extraction, and linear extraction. ${ }^{13-17}$ The results were often so poor or the rate of complications so high, that many surgeons favoured a conservative approach. ${ }^{18} \mathrm{~A}$ recently introduced technique of congenital cataract is lensectomy with anterior vitrectomy. Lensectomy along with anterior vitrectomy offers a good chance of maintaining a clear papillary axis obtaining an accurate refraction and reduces risks of vitreous incarceration in the wound and other complications.

In this study a comparative evaluation has been done between lensectomy with anterior vitrectomy and the conventional methods in the surgical management of congenital cataract.

\section{METHODS}

The present study is an interventional analytical study that entailed 30 patients (33 eyes) of bilateral or unilateral congenital cataract who attended the Ophthalmology outpatient department of LLRM Medical College, Meerut, from March 2018 to March 2019. Consecutive sampling was done and children aged between 2 and 12 years, were included in the study. Variables studied included age, sex, presenting complaints, signs, laterality, cataract morphology, ocular abnormalities, associated systemic disease and acceptance of surgery.

Patients underwent ophthalmic examination that comprised measuring uncorrected distant visual acuity in verbal children, evaluation of visual behaviours in preverbal children, oculomotor examination, slit lamp examination and fundoscopy. When the fundus was not visible, a B - scan was done to exclude retinoblastoma and to ensure that the retina was not detached. A paediatric consultation was sought in order to exclude an associated systemic disease. Those with a history of ocular trauma and uveitis were not included in the study. The choice of method for treatment was decided by simple random sampling of cases, after assigning them the numbers as they entered the study. All the cases were operated under general anaesthesia with laryngeal mask airway. The surgical techniques used in the treatment of these cases included both conventional methods of discission and discission with aspiration and the more recent methods of lensectomy and vitrectomy both limbal and pars plana type with posterior capsulotomy. The choice of method for treatment was decided by pseudorandom sampling of cases, after assigning them the numbers as they entered the study.

\section{Surgical Procedures}

\section{Discission}

A small corneoscleral incision was made at the 12 0'clock position with a von graefe's knife. The anterior capsulotomy was done with a 26 gauge angulated needle attached to a syringe. 2 - 3 stitches were given with 10 - 0 nylon in those cases, in which the corneoscleral incision was larger. The anterior chamber was formed by injecting air into it.

\section{Discission with Aspiration}

The process was similar to discission. The lens matter was sucked out by the irrigation - aspiration cannula as much as possible. 
Limbal Lensectomy and Anterior Vitrectomy

A corneoscleral incision was given at 3 or 9 0'clock position. Peripheral iridectomy was done. Vitrectomy cutter was inserted into the anterior chamber through the incision. The infusion machine was turned on and a pre-placed loop, silk suture was tightened around the cutter tip. Using the loop, the wound was sealed temporarily. Then lensectomy was done by slow and intermittent suction and cutting in order of anterior capsule, lens cortex and nucleus and finally the posterior capsule. Following complete removal of posterior capsule, anterior vitrectomy was done. Corneoscleral sutures were given to close the wound.

Pars Plana Lensectomy and Anterior Vitrectomy A limbal based conjuctival flap was made. A distance of $3.5 \mathrm{~mm}$ from the corneoscleral junction was taken as the sclerotomy site and a $3 \mathrm{~mm}$ long sclerotomy incision site was marked after using thermal cautery at the site. Sclera was then cut, until a feeling of slight give away was felt which indicated that the uvea had been reached. A preplaced 6 - 0 mattress suture was put with a loose knot. Intraocular entry was made by a von graefe's knife. The pars plana area was cut through the full 3 mm length of the sclerotomy wound. Vitrectomy cutter was inserted and the preplaced 6 - 0 silk suture was tightened around the cutter tip. Then keeping the port of vitrectomy cutter in direct vision, anterior vitrectomy was done by intermittent, slow suction and cutting.

Following this lensectomy was done. The entire nucleus was first gradually cut and aspirated out. Thereafter the anterior capsule was removed. Posterior capsulotomy was done at the end of the procedure, which prevented the posterior dislocation of lens particles. Sclerotomy wound was closed by 1 - 2 interrupted sutures of 8 - 0 monofilament silk. The conjunctival flap was closed with continuous or interrupted 8 - 0 silk sutures.

\section{Visual Rehabilitation and Amblyopia Therapy}

Surgery was immediately followed by prescription of glasses and amblyopia therapy even before removal of suture. The suture removal and repeat refraction was done at 1 month postoperatively and again at 3 months. The parents were ensured that the child should wear the prescribed glasses and occlusion therapy (for unilateral or asymmetrical cases). Contact lenses were prescribed in children with unilateral aphakia as spectacles cause aniseikonia.

\section{RESULTS}

19 of these patients (63.3\%) were males while $11(36.7 \%)$ were females with a mean age of 5 years 7 months. The maximum number of patients were in the age group of $4-8$ years in either sex ( 19 patients; $63.3 \%$ ). Among these patients 9 patients $(30 \%)$ had bilateral congenital cataract while 21 patients $(70 \%)$ had unilateral congenital lens opacities. There were 13 patients in the group that were treated by conventional approach while 20 patients were treated by lensectomy with anterior vitrectomy.

\section{Types of Cataracts}

The completeness or incompleteness of the cataracts and their subgroups were studied. 8 cataracts (24.2\%) were of complete type, with $7(21.2 \%)$ being entirely total cataract and remaining $1(3 \%)$ being membranous. 25 lenticular opacities (75.8\%) were incomplete and included zonular, nuclear, punctate fusiform, coralliform and anterior and posterior polar cataract (Table 1).

The number of cases assigned for each method of treatment was as shown in Table 2 . The vision in the remaining 7 eyes could not be ascertained because of the patients being small and uncooperative. As a result, their final visual acuity also could not be tested.

The visual acuity finally obtained in eyes with known vision was correlated with various factors which could influence the outcome of surgical treatment of congenital cataract, using different type of procedures. These factors were associated ocular defects, age at operation and type of operation done.

However, the percentage of patients with good and poor final vision in both groups i.e. with and without associated congenital abnormalities was consistent with the visual improvement in individual type of operations, both as a whole and separately, thereby signifying that the improvement in vision in cases with and without associated congenital anomalies, treated by different types of operations were not affected in their percentage by the type of operation done.

The final vision obtained also had correlation with the age at operation. It was observed that better postoperative visual acuity was obtained in those patients whose age at surgery was 4 years or more (Table 3).

The type of operative procedures applied had some relationship with the final vision also. In the present study, it was seen that better visual results were obtained with the procedure of lensectomy and vitrectomy $(61.1 \%)$ than with the conventional methods (37.5\%). The observations for this relationship are depicted in Table 4.

\section{Complications}

Total 16 (50.6\%) complications were noticed during followup. Amongst the various complications encountered posterior capsule opacification was the most common complication. 10 eyes $(40.4 \%)$ noted in either group while in patients treated with lensectomy and vitrectomy glaucoma was seen to be the commonest ( 2 eyes). Vitreous loss as a complication occurred during surgery by conventional methods in 2 eyes (8.7 \%) and was treated peroperatively by vitrectomy. Hyphema occurred as an early postoperative complication in 1 case $(4.4 \%)$. Hyphaema resolved spontaneously in 2 - 6 days. Iridocyclitis was seen in 1 eye (4.4\%), in conventionally treated group which was managed by local steroids and antibiotics.

Comparing the incidence of postoperative complications encountered with respect to the type of operative technique employed, it was observed that a higher percentage of complications were noted in those patients treated by conventional methods than in those treated with lensectomy and anterior vitrectomy.

The distribution of these complications in relation to the operative procedure employed is shown in Table 5. 


\begin{tabular}{|c|c|c|}
\hline Sl. No. & Types of Cataract & No. of Eyes \\
& Total Cataract & 7 \\
1. & Membranous Cataract & 1 \\
& Total Complete Cataract & 8 \\
2. & Incomplete Cataract & 25 \\
\hline \multicolumn{2}{|c|}{ Total } & 33 \\
\hline \multicolumn{2}{|c|}{ Table 1. Types of Cataracts and Their Distribution } \\
\hline
\end{tabular}

\begin{tabular}{|c|cc|}
\hline SI. No. & Types of Operation & No. of Cases \\
& Conventional & 13 \\
1. & Discission & 7 \\
& Discission and aspiration & 6 \\
& Lensectomy and Vitrectomy & 20 \\
2. & Limbal & 16 \\
& Pars Plana & 4 \\
\hline & Total & $\mathbf{3 3}$ \\
\hline
\end{tabular}

Table 2. The Number of Cases Assigned for Each Method of Treatment

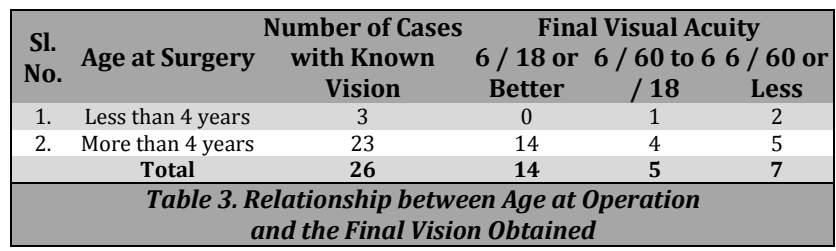

\begin{tabular}{|c|c|c|c|c|c|}
\hline \multirow{2}{*}{$\begin{array}{l}\text { Sl. } \\
\text { No. }\end{array}$} & \multirow[t]{2}{*}{ Types of Operation } & \multirow{2}{*}{$\begin{array}{l}\text { Number of } \\
\text { Cases with } \\
\text { Known Vision }\end{array}$} & $\begin{array}{r}\text { Fin } \\
6 / 18 \text { or }\end{array}$ & $6 / 60$ to & $\begin{array}{l}\text { cuity } \\
6 / 60 \text { or }\end{array}$ \\
\hline & & & Better & $6 / 18$ & Less \\
\hline \multirow{3}{*}{1.} & Conventional & 8 & 3 & 1 & 4 \\
\hline & Discission & 4 & 1 & 0 & 3 \\
\hline & Discission and aspiration & 4 & 2 & 1 & 1 \\
\hline \multirow{3}{*}{2.} & $\begin{array}{l}\text { Lensectomy and } \\
\text { Vitrectomy }\end{array}$ & 18 & 11 & 4 & 3 \\
\hline & Limbal & 15 & 9 & 3 & 3 \\
\hline & Pars Plana & 3 & 2 & 1 & 0 \\
\hline
\end{tabular}

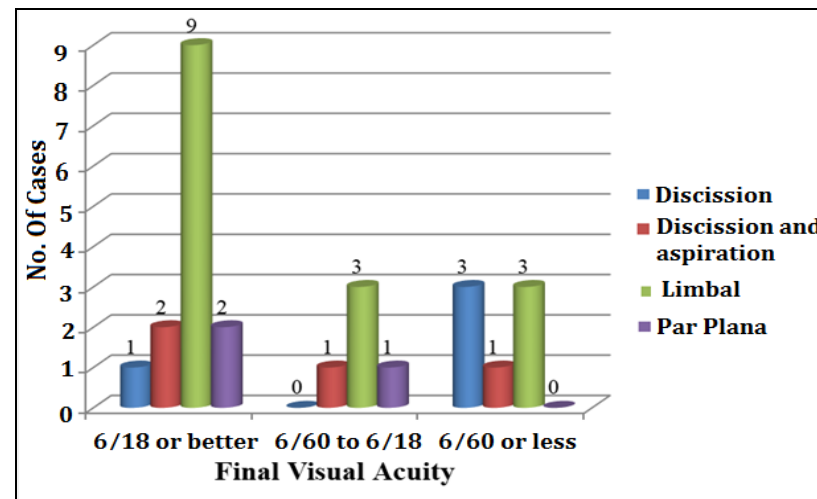

Figure 1. Bar Diagram Depicting Relationship between Types of Operation Performed and the Final Visual Acuity Attained

\begin{tabular}{|c|c|c|c|c|c|c|c|}
\hline $\begin{array}{l}\dot{0} \\
z \\
\dot{\text { मे }}\end{array}$ & 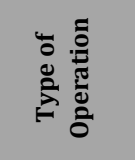 & 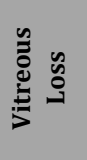 & 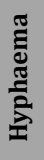 & 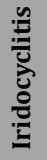 & 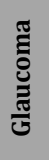 & 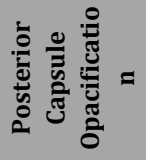 & $\frac{\pi}{0}$ \\
\hline \multicolumn{7}{|c|}{ Conventional } & 15 \\
\hline 1. & Discission & 1 & 1 & - & 1 & 7 & 10 \\
\hline 2. & $\begin{array}{l}\text { Discission \& } \\
\text { aspiration }\end{array}$ & 1 & - & 1 & - & 3 & 5 \\
\hline \multicolumn{7}{|c|}{ Lensectomy \& ANT. Vitrectomy } & 1 \\
\hline 3. & Limbal & - & - & - & 1 & - & 1 \\
\hline \multirow[t]{2}{*}{4.} & Pars Plana & - & - & - & - & - & - \\
\hline & Total & 2 & 1 & 1 & 2 & 10 & 16 \\
\hline
\end{tabular}

\section{DISCUSSION}

The present study entailed the evaluation of conventional and recent methods in the surgical treatment of congenital cataract. The results were analysed on the basis of tabulated observations, with regard to the age of patient, associated congenital anomalies, type of operation, final visual acuity and incidence of postoperative complications. Patients of either sex were included, consisting of 19 males (63.3\%) and 11 females (36.7\%).

The patients in the present study were of varying age groups and ranged from 2 to 12 years, with a mean age of 5 years 7 months. They were grouped into three sub-groups (i) $<4$ years, (ii) $4-8$ years and, (iii) $>8$ years. The study included 5 children $(16.7 \%)$ in the age group of below 4 years, 19 children $(63.3 \%)$ in the 4 - 8 years' age group and 6 children $(20.0 \%)$ in the age group of more than 8 years.

The presence of associated ocular and systemic congenital anomalies is considered to be of great significance in influencing the result of surgery, especially in terms of visual improvement. EI Traboulsi et al. in his study reported association of ocular and systemic congenital abnormalities. ${ }^{19}$ The present study also compares well with the finding of Bagley. However, there was no statistically significant difference in correlation of results after surgery depending on the type of surgery performed in groups with and without congenital defects. ${ }^{20}$ In the present study 13 cases (39.3\%) were treated conventionally using the techniques of discission in 7 cases (18.1\%). The remaining 20 eyes (60.7\%) were managed by lensectomy and anterior vitrectomy - 16 cases ( $48.5 \%$ ) by limbal route and 4 cases $(12.2 \%$ ) by using the pars plana route. (Table 2)

The results of the various types of operations were assessed on the basis of the final vision obtained in the treated eyes where visual acuity could be tested (26 eyes). The age at operation has been considered to be highly significant with regard to the final visual results. (Table 3) Studies, reporting the final visual acuity and the number of complicated cases, according to the age of patients, have considered children below and above the age of 2.5 yrs. (Keech et al.), or 4 years. ${ }^{21}$ This study reveals that in the treatment of congenital cataract, results of final visual acuity are better when the age at operation is more than 4 years. This can be easily understood when we note that surgical trauma and technical difficulties are more in the younger age group patients as also the intraoperative and post-operative precautions and care which are more demanding. Further, patients with bilateral congenital cataract and those with associated ocular congenital anomalies tend to be operated at a younger age and therefore decrease the percentage of final vision as a whole. Similarly, Magli A and Bagley also support our inference that better final visual results are correlated with operations performed at a later age in life. ${ }^{20}$

The evaluation of the various methods of surgery for congenital cataract was done by observing the results of final visual acuity and the associated incidence of complications. The conventional methods (discission and discission with aspiration) resulted in relatively poorer final vision as compared to the recent technique of lensectomy and anterior vitrectomy which resulted in a higher percentage of good final vision. (Table 4)

RJ Allen et al. also reported a higher percentage of good final vision in cases treated by lensectomy and anterior vitrectomy in comparison to the method of discission and aspiration. Thus it infers that lensectomy and anterior vitrectomy gives a higher percentage of better visual acuity as compared to the conventional methods of surgery. ${ }^{22}$ 
16 complications were noticed in the study. Of these, 15 complications were noted in conventionally treated cases whereas in lensectomy and anterior vitrectomy treated cases, 1 complication was encountered. The complications which occurred were vitreous loss in 2 cases ( $8.7 \%$ ), hyphema in 1 case $(4.4 \%)$, iridocyclitis in 1 case $(4.4 \%)$ and posterior capsule opacification in 3 cases (13\%). Gasper $\mathrm{C}$ et al. and Jingji Long et al. also found similar complications in their study. ${ }^{23,24}$

Keech et al. reported 43 complications in 38 patients out of a total of 128 cases, treated by discission with aspiration and lensectomy with anterior vitrectomy. These included 25 cases (58.2\%) of secondary membrane formation, 10 cases $(23.2 \%)$ of glaucoma, 2 cases ( $4.7 \%$ ) of retinal detachment and 6 cases $(13.9 \%)$ of anomalous angle. ${ }^{21}$

Total 8 complications were noted (Table 5) in 13 cases treated by conventional methods. In the 20 cases of lensectomy and anterior vitrectomy treated group, one complication was noticed out of 16 , which was seen in the limbal group. Tzu - Hsun Tsai et al. Srijana Adhikari Ujjowala D Shrestha reported similar complication in their studies. ${ }^{25,26}$

\section{CONCLUSIONS}

Conclusively, conventional methods are observed to be associated with a much higher incidence of complications in contrast to the recent technique of lensectomy and anterior vitrectomy which shows a significantly lesser incidence of postoperative complications.

Data sharing statement provided by the authors is available with the full text of this article at jemds.com.

Financial or other competing interests: None.

Disclosure forms provided by the authors are available with the full text of this article at jemds.com.

\section{REFERENCES}

[1] World Health Organization. Programme for the Prevention of Blindness and Deafness. Global initiative for the elimination of avoidable blindness. WHO 1997.

[2] Long E, Zhang X, Liu Z, et al. Dynamic response to initial stage blindness in visual system development. Clin Sci (Lond) 2017;131(13):151527.

[3] Medsinge A, Nischal KK. Pediatric cataract: challenges and future directions. Clin Ophthalmol 2015;9:77-90.

[4] Gilbert C, Foster A. Childhood blindness in the context of VISION 2020--the right to sight. Bull World Health Organ 2001;79(3):227-32.

[5] Rahi JS, Sripathi S, Gilbert CE, et al. Childhood blindness in India: causes in 1318 blind school students in nine states. Eye (Lond) 1995;9(Pt 5):545-50.
[6] Sheeladevi S, Lawrenson JG, Fielder AR, et al. Global prevalence of childhood cataract: a systematic review. Eye (Lond) 2016;30(9):1160-9.

[7] Johar SRK, Savalia NK, Vasavada AR, et al. Epidemiology based etiological study of pediatric cataract in Western India. Indian J Med Sci 2004;58(3):115-21.

[8] Heijl A, Leske MC. Cataract epidemiology. Ophthalmology 2007;114(1):201.

[9] Fakhoury 0, Aziz A, Matonti F, et al. Epidemiologic and etiological characteristics of congenital cataract: study of 59 cases over 10 years. J Fr Ophtalmol 2015;38(4):295-300.

[10] Elston JS, Timms C. Clinical evidence for the onset of the sensitive period in infancy. $\mathrm{Br} \mathrm{J}$ Ophthalmol 1992;76(6):327-28.

[11] Amaya L, Taylor D, Russell I, et al. Phacoaspiration in children. J Cataract Refract Surg 2001;27(10):1534-35.

[12] Lin H, Ouyang $H$, Zhu J, et al. Lens regeneration using endogenous stem cells with gain of visual function. Nature 2016;531(7594):323-8.

[13] Kuhli-Hattenbach C, Fronius M, Kohnen T. Impact of timing of surgery on outcome in children with bilateral congenital cataract. Ophthalmologe 2016;114(3):252-8.

[14] Moncreiff WF. Contributions to the surgery of congenital cataract: I. Modification of discission in the preschool age group. Am J Ophthalmol 1946;29(12):1513-22.

[15] Jones IS. The treatment of congenital cataracts by needling. Am J Ophthalmol 1961;52(3):347-55.

[16] Ziegler SL. Complete V-shaped incision for zonular and pyramidal cataracts. JAMA 1921;77:1100.

[17] Cordes FC. Linear extraction of congenital cataract surgery. Am J Ophthalmol 1961;52:355-60.

[18] Chandler PA. Surgery of congenital cataract. Am J Ophthalmol 1998;65(5):663-74.

[19] Traboulsi EI, Vanderveen D, Morrison D, et al. Associated systemic and ocular disorders in patients with congenital unilateral cataracts: the infant aphakia treatment study experience. Eye (Lond) 2016;30(9):1170-4.

[20] Bagley CH. Congenital cataracts: a survey of the various types of operation. Am J Ophthalmol 1949;32(3):411-9.

[21] Keech R, Tongue A, Scott W. Complications after surgery for congenital and infantile cataracts. Am J Ophthalmol 1989;108(2):136-41.

[22] Allen RJ, Speedwell L, Russell-Eggitt I. Long-term visual outcome after extraction of unilateral congenital cataracts. Eye (Lond) 2010;24(7):1263-7.

[23] Gasper C, Trivedi RH, Wilson ME. Complications of pediatric cataract surgery. Dev Ophthalmol 2016;57:6984.

[24] Long J, Xiang D, Guo Z, et al. Clinical characteristics and surgical procedures for children with congenital membranous cataract. J Ophthalmol 2017;2017:2370969.

[25] Tsai TH, Tsai CY, Huang JY, et al. Outcomes of pediatric cataract surgery with triamcinolone-assisted vitrectomy. J Formos Med Assoc 2017;116(12):940-5.

[26] Adhikari S, Shrestha UD. Pediatric cataract surgery with hydrophilic acrylic intraocular lens implantation in Nepalese children. Clin Ophthalmol 2018;12:7-11. 